\title{
Cytokine balance and cytokine-driven natural killer cell dysfunction in systemic juvenile idiopathic arthritis
}

\author{
Anneleen Avau ${ }^{\mathrm{a}}$, Karen Put ${ }^{\mathrm{a}}$, Carine H. Wouters ${ }^{\mathrm{b}^{*}}$ and Patrick Matthys ${ }^{\mathrm{a}^{*}}$ \\ ${ }^{a}$ Laboratory of Immunobiology, Rega Institute, Leuven, Belgium \\ ${ }^{\text {b} P e d i a t r i c ~ R h e u m a t o l o g y, ~ U n i v e r s i t y ~ H o s p i t a l ~ G a s t h u i s b e r g, ~ L e u v e n, ~ B e l g i u m . ~}$ \\ *CHW and PM contributed equally
}

Anneleen Avau, Minderbroedersstraat 10, B-3000 Leuven, Belgium, phone: +32 (0)16 337349

anneleen.avau@rega.kuleuven.be

Karen Put, Minderbroedersstraat 10, B-3000 Leuven, Belgium, phone: +32 (0)16 337349

karen.put@rega.kuleuven.be

Carine H. Wouters, Herestraat 49, B-3000 Leuven, Belgium, phone: +32 (0)16 343801

carine.wouters@uzleuven.be

Corresponding author: Patrick Matthys, Laboratory of Immunobiology, Rega Institute, Minderbroedersstraat 10, B-3000 Leuven, Belgium - patrick.matthys@rega.kuleuven.be

Phone: +32 (0)16 337349 - Fax: +32 (0)16 337340

\section{ABSTRACT}

Systemic juvenile idiopathic arthritis (sJIA) is a severe inflammatory childhood disorder, characterized by a specific pattern of systemic features and a typical cytokine profile. Patients are at risk to develop macrophage activation syndrome (MAS), an acute life-threatening condition defined by excessive proliferation and activation of macrophages and $T$ cells. Defects of unknown cause in the natural killer (NK) cell cytotoxic capacity are presumed to underlie the pathogenesis of MAS and have been detected in sJIA patients. Here, we provide an overview of the cytokine profiles in SJIA and related mouse models. We discuss the influence of cytokines on NK cell function, and hypothesize that NK cell dysfunction in SJIA is caused by altered cytokine profiles.

Key words: Systemic juvenile idiopathic arthritis - cytokine profile - IL-18 - systemic inflammatory syndromes - natural killer cells - defective cytotoxicity 


\section{Introduction}

Juvenile idiopathic arthritis (JIA) denotes a heterogeneous group of arthritic diseases of unknown origin that start before the age of 16 and persist for at least 6 weeks. Together, they represent the most common chronic rheumatic syndrome in childhood. On the basis of number of joints involved and accompanying extra-articular symptoms, 7 different subtypes of JIA are distinguished (for an overview and international classification criteria, see [1]). One of these subtypes is systemic (s)JIA, formerly known as Still's disease. sJIA is one of the most perplexing childhood disorders, exhibiting distinct disease symptoms compared to other forms of JIA. Its distinctive character is expressed by the manifestation of systemic symptoms in combination with chronic arthritis and by the absence of associations with MHC class II alleles. Extra-articular symptoms of sJIA are spiking fever, lymphadenopathy, rash, neutrophilia and thrombocytosis [2;3]. Over the past decades, the knowledge of the pathogenesis of sJIA has profoundly expanded, leading to a better understanding and eventually to better treatment strategies. A striking feature of sJIA is its association with macrophage activation syndrome (MAS). MAS is a severe, potentially life-threatening complication of several systemic inflammatory disorders, but it is most frequently observed in association with sJIA. The disease is characterized by pancytopenia, hepatosplenomegaly, coagulopathy and neurologic involvement [4;5]. The presence of hemophagocytic macrophages in bone marrow aspirates of patients and the close resemblance to a group of histiocytic disorders, collectively known as hemophagocytic lymphohistiocytosis (HLH), has led to the hypothesis of MAS being an HLH variant. HLH comprises two different conditions with comparable clinical presentation: primary or familial HLH (FHL) and secondary or acquired HLH. FHL represents a group of rare, autosomal recessive immune disorders. Secondary or acquired HLH, among which MAS is reckoned, occurs without clear genetic background, in association with any of a range of infectious agents, malignancies or autoimmune diseases [6;7]. An overview of the clinical and laboratory features of sJIA, MAS and FHL is given in Table 1.

Defects in the cytotoxic machinery of lymphocytes and natural killer (NK) cells underlie the symptoms in FHL [6]. The occurrence of comparable defects is well-documented in MAS and has also been reported in sJIA patients [8-10]. Cytotoxic cells are essential to kill infected cells. Defective cytotoxic machinery thus results in prolonged delivery of antigens, leading to excessive proliferation of $\mathrm{T}$ cells and macrophages and to escalating production of cytokines. In FHL, the decreased killing capacity originates from mutations in cytotoxicity- 
related genes. In MAS and SJIA, the decreased NK cell cytotoxicity is rather an acquired defect, presumably resulting from a disrupted cytokine environment [4;11]. In this review, we provide an overview of cytokines that are differentially expressed in sJIA when compared to healthy controls; we summarize the relation between cytokines and NK cell activity and propose a hypothesis about the influence of the cytokine environment on NK cells in sJIA.

\section{Distinct cytokine profile in sJIA patients}

The distinct clinical presentation and immunologic abnormalities in sJIA have prompted investigators to consider it as an autoinflammatory rather than an autoimmune disease [2;11]. The absence of HLA associations, the marked neutrophilia and the upregulation of innate immune pathways in gene expression profiles of sJIA patients account for this classification. Moreover, genetic polymorphisms specifically affecting innate immune gene expression have been linked to the disease, and might explain the predisposition of specific children to develop excessive inflammation to certain infectious triggers [2;12]. Classically, autoinflammatory syndromes are characterized by fever and a systemic inflammation, induced by excessive activation of the innate immune system and inappropriately high levels of inflammatory cytokines [13]. Several research groups have demonstrated a characteristic cytokine profile in sJIA, which will be discussed below. Furthermore, mouse models for sJIA (and MAS) emphasize the importance of cytokines with harmful pro-inflammatory potential.

\subsection{Cytokine analysis in sJIA patients}

Gene expression clusters in leukocytes or peripheral blood mononuclear cells (PBMCs) are indicative of a typical expression profile in sJIA, distinct from that in healthy controls and other subtypes of JIA. This was confirmed at the protein level by analysis of cytokines in the plasma of patients or after in vitro stimulation of blood cells. Table 2 summarizes inflammatory cytokines of which the expression has been explored in sJIA. Results concerning the most extensively studied cytokines, i.e. interleukin (IL)-1 $\beta$, IL-6, IL-10, IL-17, IL-18, tumor necrosis factor (TNF)- $\alpha$ and interferon (IFN)- $\gamma$, are described in detail.

Interleukin-1 $\beta$

IL-1 $\beta$ is reputed for driving inflammation in many pathological instances and for mediating bone erosion in rheumatic diseases [13;14]. In sJIA, multiple symptoms can be explained by overexpression of IL-1 $\beta$, including fever, neutrophilia, thrombocytosis and arthritis [13]. 
Polymorphisms in genes of the IL-1 family associated with sJIA have been shown for the IL-1 ligand as well as for the IL-1 receptor cluster region [15]. Although some studies demonstrated increased serum levels of IL-1 in patients with sJIA [16-18], most researchers observed an absence of a prominent IL-1 gene expression signature or significant protein levels, which led to controversy about its relevance in the disease [19-26]. Importantly, excessive production of the receptor antagonist of IL-1 $\beta$ was demonstrated in the serum of sJIA patients [16;23;24;27;28]. Nonetheless, a strong indication of the importance of IL-1 $\beta$ in sJIA came from the successful treatment of patients with the IL-1 receptor antagonist Anakinra, which resolved clinical symptoms and laboratory abnormalities [26;29;30]. Likewise, clinical trials proved the effectiveness of another IL-1 inhibitor, Canakinumab, in a substantial percentage of patients [31]. The over-representation of toll-like receptor (TLR)/IL1R pathway genes in gene expression profiles of sJIA patients further indicated indirectly an important role for IL-1 $\beta$ in the disease [20;21]. A third indication came from Pascual et al. [26], who demonstrated that serum of sJIA patients induced transcription and secretion of IL-1 $\beta$ by healthy PBMCs. They also found high amounts of IL-1 $\beta$ in the supernatants after in vitro stimulation of PBMCs of sJIA patients with PMA-ionomycin [26]. Gattorno et al. could not confirm this finding, which they attributed to the heterogeneity of the disease and the different methods used for cell activation [28]. Similarly, whole blood cultures of sJIA patients did not spontaneously release IL-1 $\beta$. Stimulation of whole blood cells with LPS or PHA resulted in IL-1 $\beta$ production yields equal to those in cultures from healthy controls [27]. Interestingly, Macaubas et al. observed that monocytes from sJIA patients responded to LPS stimulation with more IL-1 $\beta$ production than monocytes of healthy controls, but higher intracellular levels were not associated with higher levels of secreted active IL-1 $\beta$ in the supernatants. Reduced cleavage of pro-IL-1 $\beta$ into the active, secreted form may account for this divergence [32]. Loss-of-function mutations in $P 2 X 7$, which encodes an ATP membrane receptor that induces IL-1 secretion, have been described in some sJIA patients [28]. In any case, the absent IL-1 gene expression signature and the finding of normal or even reduced in vitro IL-1 $\beta$ secretion by cell cultures from sJIA patients is unexpected given the IL-1 $\beta$-related symptoms seen in sJIA and the clinical response to IL-1 inhibition. Presumably, IL-1 expression is controlled by the local microenvironments, conditioned by several other cytokines, chemokines and the restricted participation of specific cells [28]. IL-1 related symptoms may originate from IL-1 $\beta$ production by not only leukocytes but also by other cytokine-producing cells, such as fibroblasts and endothelial cells [13]. 


\section{Interleukin-6}

Evidence for a role of IL-6 in sJIA has been provided from different angles. First of all, polymorphisms in the IL-6 gene linked with enhanced IL-6 responses were demonstrated to be associated with higher susceptibility to sJIA [33;34]. Also, gene expression profiling performed on PBMCs of sJIA patients revealed an over-expression of the IL-6 gene [19;20]. When cultured in vitro, patients' PBMCs were found to produce more IL-6 than cells of healthy controls [35]. However, similar studies with whole blood cultures did not confirm such enhanced levels of spontaneous IL-6 production [27], and in vitro stimulation with LPS or PMA-ionomycin failed to show different IL-6 response rates [26;32;35]. In synovial fluid as well as in plasma of sJIA patients, elevated IL-6 levels were demonstrated and found to correlate with the overall disease activity and with some of the symptoms, such as fever, growth arrest, anemia and thrombocytosis [16-18;23;25;36-40]. However, a significant correlation between IL-6 levels in the patients and the strength of the erythropoiesis signature associated with anemia was not found, which might indicate that factors other than IL-6 contribute to the anemia in sJIA patients [41]. Finally, a clinical trial validated the use of Tocilizumab, an IL-6 inhibitor, in sJIA patients [42]. Together the data support the notion that production of IL-6 is increased in sJIA and that this plays an overall disease-promoting role.

\section{Interleukin-10}

IL-10 has profound anti-inflammatory properties, limiting excessive immune responses and preventing autoimmunity. IL-10 deficiency may therefore co-operate with other cytokinerelated abnormalities in the onset of sJIA. Increased susceptibility for sJIA has been linked to haplotypes of the IL-10 and IL 10 promoter genes associated with lower expression rates of the cytokine [43;44]. Also, IL-10 production in whole blood cultures of sJIA patients stimulated with LPS or PHA was lower than production by control cultures [27]. However, PBMCs and purified monocytes of patients contained significantly higher IL-10 mRNA levels than cells of healthy controls [19;20], and sJIA PBMC cultures produced more IL-10 whether unstimulated or stimulated in various ways, when compared to healthy control cells [35;45]. Furthermore, increased plasma levels of IL-10 in sJIA patients were shown in several reports [17;25;28;39]. Interestingly, Raziuddin et al. demonstrated an inhibitory effect of IL-10 in LPS-stimulated patients' PBMCs on the production of IL- $1 \beta$ and TNF- $\alpha$, but not IL-6. The authors therefore suggested that the in vivo anti-inflammatory effect of IL-10 may not affect IL-6 secretion [45]. The relation between IL-10 and IL-6 in sJIA was also investigated by 
Pignatti et al. [35]. In concordance with the results of Raziuddin et al., they found reduced inhibition of IL-6 by IL-10 in sJIA compared to healthy control PBMCs.

Interleukin-17

IL-17 is a typical product of Th17 cells, which orchestrate inflammatory responses by induction of IL-1, IL-6 and TNF- $\alpha$. Under certain conditions, innate cells like $\gamma \delta$ T cells were shown to dominate the IL-17 production [46]. Reports on IL-17 plasma levels in sJIA have been inconsistent, as both normal and supra-normal values were found [25;28]. Nonetheless, a larger number of IL-17-producing $\mathrm{CD}^{+} \mathrm{CD}^{+}$and $\mathrm{CD}^{+} \mathrm{CD}^{-}$cells was detected in peripheral blood of sJIA patients [47]. Hinze et al. observed a positive correlation between the erythropoiesis signature typically observed in sJIA patients and serum levels of IL-17, pointing to a potential role for IL-17 in the anemia [41].

\section{Interleukin-18}

IL-18, originally defined as IFN- $\gamma$-inducing factor, is structurally related to the IL- 1 family and uses parallel signal transduction pathways [14]. In contrast to certain other cytokines, data concerning IL-18 levels in sJIA are very consistent. Studies have indicated that excessive IL-18 plasma levels represent a good indicator for sJIA disease activity; moderately elevated amounts even remain noticeable during inactive disease [8;16;25;28;39;48-50]. In vivo, part of the total available IL-18 occurs as a complex with IL-18 binding protein (IL-18BP, [14]). Thus, the amount of biological active IL-18 depends on the ratio between these two agents. In plasma of sJIA patients, both levels were found to be elevated compared to healthy controls, but the IL-18/IL-18BP ratio was higher, due to massive IL-18 production [8;50]. Together the data emphasize the assumption that IL-18 plays a disease-promoting role in sJIA.

\section{Tumor necrosis factor- $\alpha$}

TNF- $\alpha$ is an important mediator in the development of arthritic symptoms. Although associations have been detected between sJIA and TNF- $\alpha$ gene polymorphisms correlating with high expression [51], the role of this cytokine in sJIA seems rather limited, especially when compared to its well-established central role in other rheumatic diseases, e.g. rheumatoid arthritis and JIA subtypes other than sJIA. In sJIA patients, plasma levels of TNF- $\alpha$ remained low or undetectable [17;18;23;25;28;40]. Furthermore, whole blood cultures of sJIA patients failed to spontaneously produce TNF- $\alpha$, and PBMCs stimulated with PMAionomycin did not yield higher amounts of TNF- $\alpha$ than cells of healthy controls [26;27;32]. 
The minor role of TNF- $\alpha$ in sJIA is also evident from the poor results of anti-TNF- $\alpha$ treatments that were proven to be efficacious in other subtypes of JIA [52]. This discrepancy again demonstrates the difference between sJIA and other subtypes and reflects the dominance of systemic manifestations in sJIA over arthritic symptoms.

\section{Interferon- $\gamma$}

IFN- $\gamma$, an important cytokine for macrophage activation, has well-established proinflammatory but also anti-inflammatory effects [53]. In FHL patients, IFN- $\gamma$ levels are vastly increased [54;55], and murine models for FHL point to IFN- $\gamma$ as the dominant causative cytokine [56;57]. In MAS patients, IFN- $\gamma$ levels are likewise elevated [58], and the presence of activated IFN- $\gamma$-producing lymphocytes in liver biopsies of MAS patients suggests that the cytokine has a pro-inflammatory role in the disease [59]. However, controversy exists about the relevance of IFN- $\gamma$ in sJIA. Although Ishikawa et al. identified an upregulated expression of a network of genes in which IFN- $\gamma$ was the central molecule [60], a remarkable absence of IFN- $\gamma$ induced gene expression was shown by Fall et al. [21]. Likewise, other gene expression studies did not report an increased IFN- $\gamma$ signature [19;20;41]. Sikora et al. demonstrated that the restricted IFN- $\gamma$-induced genetic signature was not the result of hyporesponsive monocytes to IFN- $\gamma$ stimulation in vitro [61]. They consequently hypothesized that limited exposure to IFN- $\gamma$ was a more convenient explanation for the phenomenon. In line with the ex vivo gene expression results concerning IFN- $\gamma$, no evidence was found for higher IFN- $\gamma$ production by patients' PBMCs in vitro [45]. However, a higher proportion of IFN- $\gamma$-producing $\mathrm{T}$ cells was demonstrated in the peripheral blood of sJIA patients in comparison with pediatric age-matched healthy controls [47]. In plasma of patients, Gattorno et al. demonstrated elevated levels of IFN- $\gamma$ and interferon-inducible protein 10, whereas others mention undetectable IFN- $\gamma$ levels [25;28;40]. We recently found increased IFN- $\gamma$ in plasma of sJIA patients, but the levels were low especially in comparison with their high IL-6 and IL-18 levels (data not shown). Prahalad et al. demonstrated a significant increase in IFN- $\gamma$ serum levels of 77 JIA patients compared to healthy controls, of which 10 were diagnosed with sJIA. However, levels were lower than $5 \mathrm{pg} / \mathrm{ml}$ in $>90 \%$ of the patients and the median was $\sim 0 \mathrm{pg} / \mathrm{ml}$ [17]. Thus, the role of IFN- $\gamma$ in sJIA remains subject of further investigations. 
To summarize, studies on sJIA patients are supportive for pathogenesis-promoting roles of IL-1 $\beta$, IL-6 and IL-18. Uncertainty reigns as to possible roles of IL-10, IL-17 and IFN- $\gamma$; the role of TNF- $\alpha$ seems limited. The joint occurrence of excessive IL-18 levels and only moderately elevated levels of IFN- $\gamma$ in sJIA patients is rather surprising, given the stimulatory role of IL-18 on NK cell IFN- $\gamma$ production. Possibly, IL-18 is not the main stimulator of IFN- $\gamma$ in sJIA, or the relation between IL-18 and IFN- $\gamma$ is defective in the disease, as suggested by de Jager et al. [8], which might indicate a subordinate or even protective role for IFN- $\gamma$ in sJIA.

sJIA consists of a heterogeneous group of patients; some patients seem more prone to develop MAS than others [62]. A number of studies have focused on establishing correlations between a predominance of particular inflammatory cytokines and clinical profiles or responsiveness to therapy. Gattorno et al. observed a distinct response to Anakinra [28]. About half of the patients with sJIA improved at first, but relapsed after some time. Arthritic symptoms were especially difficult to control in this group. The other half were complete responders, with immediate control of systemic and articular symptoms. Fall et al. identified a 'normal-ferritin' and a 'high-ferritin' group of sJIA patients, the latter ones also displaying other symptoms specific for MAS [21]. Shimizu et al. proposed a coinciding subdivision based on plasma cytokine profiles into an IL-6-dominant and an IL-18-dominant group, the former one presenting mainly arthritic symptoms and the latter one being prone to develop MAS. The different responses of patients to IL-1 $\beta$ and IL- 6 blockade could also be explained by this subdivision, with an IL-1 $\beta / \mathrm{IL}-18$ dominant group that responds well to Anakinra, and an IL-6-dominant group that responds to Tocilizumab [48;63]. However, IL-1 $\beta$ or IL-6 blockade have proven to be effective regardless of arthritis. In addition, we could not confirm this subdivision of patients based on IL-6 or IL-18 expression; patients with MAS complicating sJIA even expressed higher levels of IL-6 than sJIA patients without MAS (data not shown). Cytokine expression in sJIA patients is even more complex as it may shift with successive phases of the disease. As a consequence, patients may initially gain benefit from one particular treatment, but need other forms of therapy later on. In general, sJIA can be seen as a multilayered complex disease, with many aspects contributing to its development and to its predisposition for MAS. 


\subsection{Cytokine analysis in mouse models of sJIA}

Analysis of disease mechanisms in mouse models that mimic certain aspects of sJIA can clarify the role of cytokines in the human disease. Table 3 presents an overview of cytokines detected in three such models.

A first mouse model, described by De Benedetti et al., provided evidence suggestive for a role of IL-6 production in causing growth impairment, a well-known feature of sJIA (and other chronic inflammatory diseases of childhood) particularly evident during periods of augmented disease activity [12;64]. In NSE/hIL-6 mice, the rat neurospecific enolase (NSE) promoter drives the expression of human IL-6 cDNA in mature neuron and neuroendocrine cells. Growth defects were observed in lines with peripheral expression of IL-6 [64]. Although the mice did not present signs of arthritis, the model does support the possibility that chronic high levels of circulating IL-6 augment the susceptibility of sJIA patients for MAS. Indeed, administration of TLR ligands to the IL-6-transgenic mice resulted in increased ferritin levels, high serum IL-1 $\beta$, IL-18 and TNF- $\alpha$ concentrations and hematologic abnormalities typical of MAS [65]. The chronically high IL-6 levels seen in sJIA patients might cause a hyper-responsiveness to TLR ligands, resulting in triggering of MAS after infections. Of note, this mouse model tends to conflict with the subdivision of sJIA patients in an IL-6-dominant group with arthritis and an IL-18-dominant group, prone to develop MAS.

A second model of Kawane et al. addresses the role of cytokines released by activated macrophages in causing joint inflammation. DNase II-null mice accumulate undigested DNA in lysosomes of macrophages, resulting in lethal anemia in mouse embryos. By using inducible knock-outs for DNase II, it was demonstrated that accumulation of undigested DNA in macrophages caused prolonged macrophage activation in adult mice. This activation in turn resulted in a chronic arthritis and increased TNF- $\alpha$, IL- $1 \beta$ and IL-6 mRNA levels in the affected joints [66]. Although IL-1 $\beta$ and IL-6 could not be detected in the serum, blockade of these cytokines rescued mice from the symptoms. High serum IL-18 levels were demonstrated, but inhibition of IL-18 did not relieve the symptoms. This mouse model indicates that persistent systemic activation of macrophages maintains a cytokine storm that, due to locally accumulating DNA, extends to the joint tissue, resulting in arthritic symptoms.

A third model of sJIA relies on the injection of complete Freund's adjuvant (CFA, containing heat-killed mycobacteria) in WT and IFN- $\gamma$-deficient BALB/c mice [67]. The mice developed arthritis and many systemic inflammatory symptoms that resembled those of sJIA, particularly in the absence of IFN- $\gamma$, pointing to a dispensable or even protective role in this model. IL-6 levels were substantially increased in the serum of the CFA-injected 
IFN- $\gamma$-deficient mice, while mRNA analysis of lymph node cells revealed increased expression of IL-1 $\beta$ and IL-18. Increased IL-17 production by lymph node cells was shown in vitro. Likewise, the number of IL-17 producing $\gamma \delta \mathrm{T}$ cells was elevated. Antibodies against IL-17 or against the p40 subunit of IL-12 and IL-23 prohibited the majority of symptoms in the mice. These observations point to innate and adaptive IL-17 producing T cells as harmful agents in the syndrome. In patients, increased IL-1 $\beta$ and IL-18 may cooperate with IL-23 to induce IL-17 production by innate cells, like $\gamma \delta \mathrm{T}$ cells and invariant NKT cells [68]. CFA-injected IFN- $\gamma$ deficient mice did not develop liver failure or increased ferritin levels. The appearance of arthritis without clear MAS-like symptoms indicates that this mouse model may serve as a model for IL-6-related, arthritis-prominent sJIA.

To summarize, animal models of sJIA endorse the central role of IL-1 $\beta$, IL-6 and IL-18 in the immune disorder. Furthermore, the models confirm the assumption that TNF- $\alpha$ plays a limited role [64;66;67], while IFN- $\gamma$ seems of subordinate importance or may even be protective [67]. In spite of the uncertain role of IFN- $\gamma$ in sJIA, MAS patients were shown to have increased IFN- $\gamma$ production [58;59]. However, Canna et al., working with a model of MAS, demonstrated that IFN- $\gamma$ was dispensable for the majority of MAS-like symptoms in the absence of IL-10 [69]. The model relied on repeated TLR9 stimulation in WT mice [70]. Disruption of IL-10 resulted in a more severe disease, indicated by the authors as 'fulminant MAS' [69]. Levels of IL-6, IL-12p70, IL-18 and IFN- $\gamma$ were significantly increased in mice with fulminant MAS in comparison with untreated control mice. In the more severe disease conditions, i.e. fulminant MAS, IFN- $\gamma$ was not the causative agent, although increased levels were seen.

\section{NK cell activity and cytokines}

Natural killer (NK) cells are large, granular lymphocytes that play a fundamental role in fast responses against pathogen-infected and tumor cells. NK cells are activated through stimulation of activating receptors by NK-activating ligands, such as viral agents or stress antigens. In parallel, inflammatory cytokines are needed for optimal triggering of the effector functions. Inhibitory receptors are crucial to avoid reactivity against 'self'; the balance of activating and inhibitory receptors determines the outcome of NK cell triggering [71-73] 
3.1. NK cell activity: cytotoxicity and cytokine production

NK cells kill target cells in a fast way via the granule exocytosis pathway and the death receptor pathway [73]. The first mechanism relies on the exocytosis of cytotoxic granules. The main granule-associated proteins are granzymes, serine proteases that mediate apoptosis after uptake, and perforin, which targets the granzymes into the target cells. The second mechanism is based on binding of members of the TNF family of cytokines expressed on NK cells to their receptors on target cells, leading to caspase-dependent target cell apoptosis. NK cell cytotoxicity is activated mainly in response to IFN- $\alpha / \beta$ and IL-15 [72;73].

In addition to target cell killing, NK cells are important producers of chemokines and cytokines, resulting in recruitment of immune cells and amplification of the immune response. In humans, two NK cell subsets with different functions and homing properties have been described, based on the expression of cell surface markers. The CD3-CD56 ${ }^{\mathrm{dim}}$ CD $16^{+}$ population, which accounts for $\sim 90 \%$ of peripheral blood and spleen NK cells, has high cytotoxic activity and displays low cytokine production. The $\mathrm{CD}^{-} \mathrm{CD} 56^{\text {bright }} \mathrm{CD} 16^{-}$cells, which reside principally in lymph nodes and tonsils, mainly produce cytokines, such as IFN- $\gamma$, TNF- $\beta$, IL-10, IL-13 and granulocyte-macrophage colony-stimulating factor (GM-CSF) [71;74]. Whether NK cells can switch from one type into another, or whether the CD56 $6^{\text {bright }}$ NK cells are precursors of CD56 ${ }^{\mathrm{dim}}$ NK cells, is subject of ongoing research. In mice, three NK subsets can be defined via expression of CD11b and CD27, with CD11b ${ }^{\text {dull }} \mathrm{CD} 27^{+} \mathrm{NK}$ cells corresponding to CD56 ${ }^{\text {bright }}$ human NK cells based on phenotype and anatomical localization [71]. Mouse NK cells differ in several aspects from human NK cells, for instance by the absence of CD56 expression. Thus, care should be taken when translating data from mice to the human situation.

\subsection{Influence of inflammatory cytokines on NK cell function in vitro}

The differentiation and activation of NK cells is influenced by specific cytokines produced within the time window and local niche where stimulation takes place. In vitro studies have provided partial understanding of this complex interplay. Important cytokines involved in NK cell function are IL-12, IL-15, IL-18, IL-21 and IFN- $\alpha / \beta$, but participation of additional ones has been described (reviewed in [72;75]). Furthermore, defects in NK cell development and function were shown in mice in the absence of IL-2, IL-12, IL-15, IL-18 and IFN- $\gamma$ [67;7679]. In vitro experiments with human NK cells demonstrated that IL-12+IL-18 is the optimal cytokine combination for induction of IFN- $\gamma$. IL-12, combined with IL-2 or IL-15, was found 
particularly capable to elicit IL-10 production. The optimal combination of cytokines for GM-CSF production was found to be IL-15+IL-18, which also led to IL-13 and TNF- $\beta$ production (Figure 1A) [74;80;81]. Mouse NK cells were demonstrated to produce IFN- $\gamma$ upon stimulation with IL-12 combined with IL-18. IL-10 expression was induced after IL-12 or IL-21 in combination with IL-2 or IL-15, while IL-18 stimulation, combined with IL-2 or IL-15, led to increased IL-13 and GM-CSF (Figure 1B) [82-85].

Most in vitro studies rely on stimulation of NK cells with cytokines for a short period of time, thus mimicking acute viral infections in vivo. Brady et al. studied mouse NK cell phenotypes following 7-day long in vitro exposure to distinct combinations of cytokines [82], which may mimic the situation in vivo in autoinflammatory syndromes. Whereas IL-15 alone induced massive proliferation, the induction was antagonized by a multitude of cytokines, including IL-4, IL-12, IL-18 and IL-21, and the immunosuppressive cytokine TGF- $\beta$, but not by IL-10. The reduction in cell number was accompanied by increased cell size, granularity and an elevated amount of propidium iodide positive cells, indicating that the decreased cell count was caused by differentiation into effector NK cells and upregulation of apoptosis. NK cell cytotoxicity was likewise affected by distinct cytokine combinations. IL-15 and IL-21 induced killing of target cells by NK cells, whereas IL-12, IL-18 and IL-4 antagonized this induction without affecting perforin expression or degranulation. IL-10 and TGF- $\beta$ had no effect on killing capacity. Taken together, the cytokine milieu controls NK cell differentiation and function during inflammatory reactions. With exception of IL-21, inflammatory cytokines induced a 'helper' type of NK cells that produced a specific palette of cytokines, and showed depressed cytotoxicity [82;83].

\section{NK cells in SJIA: influenced by the cytokine environment?}

Multiple characteristics of sJIA, and especially of sJIA complicated by MAS, correspond to symptoms of FHL. In this disease, loss-of-function mutations in cytotoxicity-related genes account for the uncontrolled immune response by excessive proliferation of macrophages and $\mathrm{T}$ cells. It is possible that failure to remove infected cells by defective cytotoxic cells results in the continuous stimulation of the immune system. On the other hand, unsuccessful removal of antigen presenting cells and activated $\mathrm{T}$ cells after clearance of the infection may likewise results in ongoing cytokine secretion. This hypothesis is supported by the fact that an infectious trigger cannot always be found in patients [9]. Mutations in the perforin gene PRF1 are frequently encountered in FHL; other missense mutations are described in UNC13D, 
STX11 and STXBP2, which all play a role in granule exocytosis [6]. In acquired forms of HLH, like MAS, and in sJIA, symptoms comparable to those of FHL are seen without clear evidence for a genetic cause. The suspected pivotal role of NK cells in sJIA - complicated by MAS - stimulated profound investigation of these cells in the disease.

\subsection{NK cell numbers in sJIA}

Reports about NK cell numbers in sJIA are not unanimous. While some research groups reported normal numbers of NK cells in patients [10;27;86], Fall et al. found mildly decreased numbers of $\mathrm{CD}^{\text {bright }}$ as well as CD56 $6^{\mathrm{dim}} \mathrm{NK}$ cells in patients' PBMCs [21]. Two independent groups demonstrated a significant decrease of NK cell counts in whole-blood samples of sJIA patients compared to samples of patients with other types of JIA or healthy controls [87;88]. Furthermore, NK cell numbers were found to be negatively correlated with disease activity [87]. The reduction of NK cell numbers in sJIA could be explained by a shortage of cytokines that induce their proliferation, such as IL-2 and IL-15, combined with increased apoptosis induced by specific cytokines. Indeed, a study by de Jager et al. failed to demonstrate significant increases of IL-2 or IL-15 levels in patients with sJIA when compared to healthy controls, whereas IL-18 levels were strongly elevated [25]. Shibatomi et al. demonstrated a negative correlation between serum levels of IL-18 and NK cell numbers [89]; in vitro analysis showed caspase-dependent NK cell death in response to IL-12 and IL-15 when combined to IL-18. This observation corresponds to the study by Brady et al., in which apoptosis was found to be induced by chronic stimulation with IL-4, IL-12, IL-18 and IL-21 [82]. Reduced NK cell numbers have also been reported in systemic autoimmune diseases, such as systemic lupus erythematosus [90], in which high IL-18 levels were proven to correlate with disease severity [91]. Likewise, a negative correlation between IL-18 and absolute NK cell numbers has been shown in HIV-patients [92].

\subsection{NK cell cytotoxicity in sJIA}

The cytolytic activity of NK cells was found to be suppressed in a number of sJIA patients [8;10;88;93]. This defect distinguishes sJIA from other clinical forms of childhood arthritis and may explain the specific predisposition of sJIA patients to develop MAS. The reduced killing capacity was not solely a consequence of decreased NK cell numbers, nor of the steroid treatment. Rather, a combination of patient-specific genetic and acquired factors may be held responsible [10;93;94]. Indeed, Grom et al. demonstrated reduced perforin expression in sJIA patients complicated by MAS, illustrating a common pathway between sJIA, MAS 
and FLH [93]. Vastert et al. detected heterozygous missense mutations in the perforin gene in subsets of sJIA patients [95]. In a study of Wulffraat et al., the reduced perforin expression in sJIA patients was shown to be restored by autologous hematopoietic stem cell transplantation, indicating that the low perforin production was not simply caused by genetic defects but rather by suppressed transcription in at least part of the patients [94]. Thus, the cytokine environment may be held responsible for the lower NK cytotoxicity in sJIA, not only by affecting perforin expression, but perhaps also by altering expression of other genes and activation pathways in NK cells [9;96]. Since IL-18 is a well-known stimulator of NK cell activity, research was performed to elucidate the remarkable finding of high IL-18 plasma levels and simultaneously low NK cell activity. IL-18 from patients was found to be functional, as the cytolytic capacity of PBMCs obtained from healthy controls was significantly increased in vitro after incubation with plasma of sJIA patients. However, the response of patient NK cells to exogenous IL-18 was impaired, resulting from a defective phosphorylation of the IL-18 receptor [8]. It still needs to be explored if this defect is the result of exhaustion or of lower sensitivity to IL-18, which are both reversible, or if a genetic factor is involved. Dysfunctional NK cells were also demonstrated in other systemic rheumatic diseases. Systemic lupus erythematosus patients, for example, develop decreased killing capacity in addition to decreased numbers of active NK cells, and this is related to disease severity and outcome [90;97]. Increased serum IL-6 may also account for decreased NK cell numbers and function [98].

Less research has been performed to investigate the NK cell activity in sJIA with respect to cytokine production. Exogenous IL-18 was unable to increase IFN- $\gamma$ production by purified NK cells of sJIA patients, in contrast to cells of healthy controls or of polyarticular JIA patients [8], endorsing the previous assumption that sJIA NK cells are hyporesponsive to IL-18. However, stimulating patients' PBMCs with PMA/ionomycin resulted in significantly higher percentages of IFN- $\gamma^{+}$and TNF- $\alpha^{+}$NK cells when compared to PBMCs from healthy control or from patients with oligo- or polyarticular JIA [88].

\subsection{Hypothesis about the link between NK cell defects and cytokine profiles}

A growing body of literature addresses defects in NK cell function in chronic systemic inflammatory syndromes. It can be hypothesized that the cytokine environment is responsible for these observations (Figure 2). Cytokine balances are changed in chronic immune disorders most likely because of a failure to turn off immune responses, or because of continuous stimulation of hematopoietic and non-hematopoietic cells with danger signals. In sJIA 
patients, macrophages, dendritic cells and other cells, such as fibroblasts and endothelial cells, produce high levels of inflammatory cytokines, such as IL-18. Environmental triggers and genetic predisposition may account for these chronic high levels. One of the consequences of the higher cytokine levels is over-activation or exhaustion of NK cells. More specifically, as seen in the study of Brady et al., continuous high levels of IL-18 together with other cytokines, like IL-6, may induce an NK cell 'helper' phenotype, with low cytotoxic activity but high producing capacity of a specific palette of cytokines, accompanied by increased apoptosis [82]. The presence of cytokines like IL-2, IL-15 and IL-21, that induce proliferation and cytotoxicity, may be less explicit. Reduced NK cell numbers and reduced cytotoxicity will lead to decreased killing of activated immune cells, thereby worsening the disease symptoms and resulting in a vicious circle. Besides polymorphisms in cytokine genes, which may account for increased production in response to immune stimulation, some sJIA patients were shown to display polymorphisms in genes of the cytotoxic machinery. These polymorphisms may equally contribute to the vicious circle. Of note, evidence emerges for the presence of 'regulatory' NK cells in systemic infections, which produce high amounts of IL-10 [99;100]. It will be of interest to study this subset in chronic inflammatory immune disorders such as sJIA and MAS. Potentially, the typical cytokine environment in sJIA does not favor the formation of regulatory NK cells, further stimulating the ongoing inflammatory response.

\section{Conclusion}

sJIA is unique compared to other subtypes of JIA, given its systemic character and its intriguing predisposition to develop MAS. A pivotal role in the pathogenesis of sJIA has been contributed to the distinct cytokine environment, with IL-1 $\beta$, IL-6 and IL-18 as most important cytokines. Especially IL-18 seems to play a dominant role in the NK cell defects. Thus, continuous high plasma levels of IL-18 may lead to apoptotic or hyporesponsive NK cells in sJIA patients. The predisposition of subsets of patients to develop MAS probably results from the depressed NK cell number as well as NK cell function provoked by high IL-18, with defective killing of hyperactive macrophages as a consequence. Inhibition of IL-18, e.g. by IL-18 binding protein, would therefore form an alternative treatment strategy for sJIA patients complicated by MAS. Pediatric rheumatologists are more and more convinced to use biological agents in the early treatment of sJIA, with promising results. The outcome of these treatment strategies differs between patients, given the heterogeneity of the 
disease resulting from different genetic and environmental factors. Care should be taken with these biological agents, since inhibitors of cytokines may create an unfavorable imbalance in the cytokine network with a risk for complications. Further research is needed to elucidate the role of continuous high levels of inflammatory cytokines on NK cell function and to translate this into optimally targeting treatment strategies for sJIA patients.

\section{Acknowledgments and financial contribution}

The authors thank Prof. Alfons Billiau and Prof. George Leclercq for critical revision of the manuscript. This work was supported by grants from the Fund for Scientific ResearchFlanders (FWO-Vlaanderen), the Regional Government of Flanders (GOA program) and the Interuniversity Attraction Poles (IAP). A.A. and K.P. received a fellowship from the FWOVlaanderen. The authors declare no competing financial interests. 
Figures and Tables

Table 1 | Symptoms of sJIA, MAS and FHL

\begin{tabular}{|c|c|c|c|c|}
\hline & & SJIA & MAS & FHL \\
\hline & references & [1-3;9;12;101;102] & {$[4 ; 6 ; 7 ; 9 ; 12 ; 101 ; 103-105]$} & {$[6 ; 7 ; 9 ; 105-112]$} \\
\hline & incidence & $\sim 1 / 100000$ & unknown & $\sim 0.12 / 100000$ \\
\hline \multirow{9}{*}{ 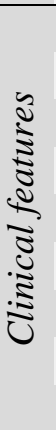 } & fever & quotidian & persistent & persistent \\
\hline & rash & evanescent & petechial/macular & maculopapular \\
\hline & mucosal bleeding & - & + & + \\
\hline & hepatomegaly & + & + & + \\
\hline & splenomegaly & + & + & + \\
\hline & lymphadenopathy & + & + & + \\
\hline & arthritis & + & - & - \\
\hline & serositis & + & - & - \\
\hline & CNS dysfunction & $-/+$ & + & + \\
\hline \multirow{19}{*}{ 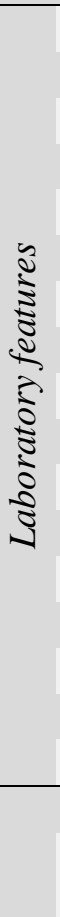 } & neutrophil count & $\uparrow \uparrow$ & $\downarrow$ & $\downarrow$ \\
\hline & platelet count & $\uparrow \uparrow$ & $\downarrow$ & $\downarrow$ \\
\hline & anemia & + & + & + \\
\hline & ESR & $\uparrow \uparrow$ & normal or sudden $\downarrow$ & normal or $\downarrow$ \\
\hline & CRP & $\uparrow$ & $\uparrow$ & $\uparrow$ \\
\hline & bilirubin & normal & normal or $\uparrow$ & $\uparrow$ \\
\hline & ALT/AST & normal or $\uparrow$ & $\uparrow \uparrow$ & $\uparrow \uparrow$ \\
\hline & PT & normal & $\uparrow$ & $\uparrow$ \\
\hline & PTT & normal & $\uparrow$ & $\uparrow$ \\
\hline & fibrinogen & $\uparrow$ & $\downarrow$ & $\downarrow$ \\
\hline & ferritin & normal or $\uparrow$ & $\uparrow \uparrow$ & $\uparrow \uparrow$ \\
\hline & D-dimers & $\uparrow$ & $\uparrow \uparrow$ & $\uparrow \uparrow$ \\
\hline & sCD25 & normal or $\uparrow$ & $\uparrow \uparrow$ & $\uparrow \uparrow$ \\
\hline & hypoalbuminemia & - & + & + \\
\hline & hyponatremia & - & + & + \\
\hline & hypertriglyceridemia & - & + & + \\
\hline & sCD163 & normal or $\uparrow$ & $\uparrow \uparrow$ & $\uparrow \uparrow$ \\
\hline & NK cell dysfunction & possible & frequent & common \\
\hline & $\begin{array}{l}\text { Hemophagocytic } \\
\text { macrophages }\end{array}$ & possible & frequent & very frequent \\
\hline
\end{tabular}

+, often diagnosed; -, not diagnosed/described; $\uparrow \uparrow$, strong increase; $\uparrow$, increase; $\downarrow$, decrease. Abbreviations: ALT/AST, alanine aminotransferase/aspartate aminotransferase; CNS, central nervous system; CRP, C-reactive protein; ESR, erythrocyte sedimentation rate; HLH, hemophagocytic lymphohistiocytosis; MAS, macrophage activation syndrome; NK, natural killer; PT, prothrombin time; PTT, partial thromboplastin time; sCD, soluble cluster of differentiation; sJIA, systemic juvenile idiopathic arthritis. 
Table 2| Cytokines in sJIA: ex vivo mRNA levels, in vitro production and plasma levels

\begin{tabular}{|c|c|c|c|c|c|c|}
\hline & \multicolumn{4}{|c|}{ Production by leukocytes } & \multicolumn{2}{|r|}{ Plasma level } \\
\hline & & $x v^{\prime} \operatorname{sivo}^{\mathrm{a}}$ & & in vitro ${ }^{b}$ & & \\
\hline IL-1 $\beta$ & $\leftrightarrow$ & [19-22] & $\uparrow, \downarrow, \leftrightarrow$ & {$[26-28 ; 32]$} & $\uparrow, \downarrow, \leftrightarrow$ & [16-18;23-26;28] \\
\hline IL-1Ra & ND & & $\leftrightarrow$ & {$[27 ; 28]$} & $\uparrow \uparrow$ & {$[16 ; 23 ; 24 ; 27 ; 28]$} \\
\hline IL-4 & ND & & $\uparrow, \leftrightarrow$ & {$[45 ; 47]$} & $\uparrow, \leftrightarrow$ & {$[25 ; 28]$} \\
\hline IL-6 & $\uparrow$ & {$[19 ; 20]$} & $\uparrow, \leftrightarrow$ & {$[26 ; 27 ; 32 ; 35]$} & $\uparrow \uparrow$ & {$[16-18 ; 23 ; 25 ; 28 ; 37 ; 39 ; 40 ; 48 ; 49]$} \\
\hline IL-7 & ND & & ND & & $\uparrow$ & {$[28 ; 113]$} \\
\hline IL-8 & ND & & ND & & $\uparrow, \leftrightarrow$ & {$[17 ; 18]$} \\
\hline IL-10 & $\uparrow$ & {$[19 ; 20]$} & $\uparrow, \downarrow, \leftrightarrow$ & {$[27 ; 32 ; 35 ; 45]$} & $\uparrow, \leftrightarrow$ & {$[17 ; 25 ; 28 ; 39]$} \\
\hline IL-12 & ND & & ND & & $\uparrow$ & {$[18 ; 25 ; 28]$} \\
\hline IL-13 & ND & & ND & & $\uparrow, \leftrightarrow$ & {$[25 ; 28]$} \\
\hline IL-17 & ND & & $\uparrow$ & [47] & $\uparrow, \leftrightarrow$ & {$[25 ; 28]$} \\
\hline IL-18 & $\uparrow$ & [50] & $\leftrightarrow$ & [28] & $\uparrow \uparrow$ & {$[8 ; 16 ; 25 ; 28 ; 39 ; 48-50]$} \\
\hline TNF- $\alpha$ & ND & & $\leftrightarrow$ & {$[26 ; 27 ; 32]$} & $\uparrow, \leftrightarrow$ & {$[17 ; 18 ; 23 ; 25 ; 28 ; 40]$} \\
\hline IFN- $\gamma$ & $\leftrightarrow$ & [21] & $\uparrow, \leftrightarrow$ & {$[45 ; 47]$} & $\uparrow, \leftrightarrow$ & {$[25 ; 28 ; 40]$} \\
\hline G-CSF & ND & & ND & & $\uparrow \uparrow$ & [28] \\
\hline GM-CSF & ND & & ND & & $\uparrow \uparrow$ & [28] \\
\hline
\end{tabular}

a mRNA level in PBMCs or whole blood cells; 'protein level after stimulation of leukocytes with LPS, PMA-ionomycin, PHA or ant-CD3/CD28 in vitro; $\uparrow$, elevated; $\uparrow \uparrow$ strongly elevated; $\leftrightarrow$ undetectable or not elevated; $\downarrow$, lower than healthy controls; more than one symbol, conflicting results in literature. Abbreviations: G-CSF, granulocyte-colony stimulating factor; GM-CSF, granulocyte macrophage-colony stimulating factor; IFN, interferon; IL, interleukin; ND, not described; Ra, receptor antagonist; TNF, tumor necrosis factor.

Table 3 | Cytokine expression in mouse models for sJIA and MAS [64-67;69;70]

\begin{tabular}{|c|c|c|c|c|c|c|c|c|c|c|c|c|c|c|c|c|c|}
\hline & & \multicolumn{16}{|c|}{ Cytokine level } \\
\hline & & \multicolumn{2}{|c|}{ IL-1 $\beta$} & \multicolumn{2}{|c|}{ IL-6 } & \multicolumn{2}{|c|}{ IL-10 } & \multicolumn{2}{|c|}{ IL-12 } & \multicolumn{2}{|c|}{ IL-17 } & \multicolumn{2}{|c|}{ IL-18 } & \multicolumn{2}{|c|}{ TNF- $\alpha$} & \multicolumn{2}{|c|}{ IFN- $\gamma$} \\
\hline & & A & B & A & B & A & B & A & B & A & B & A & B & A & B & A & B \\
\hline \multirow{3}{*}{$\underset{⿱ 亠 凶}{\mathbb{S}}$} & de Benedetti et al. & ND & ND & $+^{\mathrm{a}}$ & + & $\mathrm{ND}$ & ND & ND & ND & ND & ND & ND & ND & ND & ND & ND & ND \\
\hline & Kawane et al. & $++^{\mathrm{b}}$ & ND & $++^{\mathrm{b}}$ & ND & $++^{\mathrm{b}}$ & ND & ND & ND & $++^{\mathrm{b}}$ & ND & $++^{\mathrm{b}}$ & + & $++^{\mathrm{b}}$ & ND & ND & ND \\
\hline & Avau et al. & $+^{\mathrm{c}}$ & - & $\pm^{\mathrm{d}}$ & + & $++^{\mathrm{c}, \mathrm{d}}$ & - & ND & ND & $+^{\mathrm{C}}$ & + & $+^{\mathrm{C}}$ & - & - & - & ND & ND \\
\hline \multirow{2}{*}{$\sum_{z}^{\infty}$} & Strippoli et al. & ND & + & $\mathrm{ND}$ & + & $\mathrm{ND}$ & ND & ND & ND & ND & ND & ND & + & $\mathrm{ND}$ & + & ND & ND \\
\hline & $\begin{array}{l}\text { Behrens et al., } \\
\text { Canna et al. }\end{array}$ & ND & - & ND & + & ND & + & ND & + & ND & ND & $\mathrm{ND}$ & + & ND & - & $+^{e}$ & + \\
\hline
\end{tabular}

\section{Influence of cytokine blockade on phenotype}

\begin{tabular}{c|lcccccccc}
\multicolumn{1}{l}{} & IL-1 $\beta$ & IL-6 & IL-10 & p40 & IL-17 & IL-18 & TNF- $\alpha$ & IFN- $\gamma$ \\
\hline \multirow{2}{*}{} & Kawane et al. & $\downarrow$ & $\downarrow$ & ND & ND & ND & $=$ & $\downarrow$ & ND \\
& Avau et al. & ND & ND & ND & $\downarrow$ & $\downarrow$ & ND & ND & $\uparrow$ \\
\hline \multirow{2}{\infty}{} & Behrens et al., & ND & ND & $\uparrow$ & $\downarrow^{\mathrm{g}},=^{\mathrm{h}}$ & ND & ND & $=$ & $\downarrow^{\mathrm{g}},=^{\mathrm{h}}$
\end{tabular}

A, mRNA level in ${ }^{a}$ heart and lung tissue, ${ }^{b}$ joints, 'lymph node cells, ${ }^{\mathrm{d}}$ blood cells, ${ }^{\mathrm{e}}$ liver cells; B, protein level in plasma; ${ }^{f}$ subunit of IL-12 and IL-23; ${ }^{g}$ in WT mice; hin the absence of IL-10; +, significantly increased; -, not increased; \pm , increased, although not significant; $\uparrow$, inhibition leads to worse symptoms; =, inhibition does not change the symptoms; $\downarrow$, inhibition prohibits the symptoms. Abbreviations: IFN, interferon; IL, interleukin; MAS, macrophage activation syndrome; ND, not determined; sJIA, systemic juvenile idiopathic arthritis; TNF, tumor necrosis factor. 


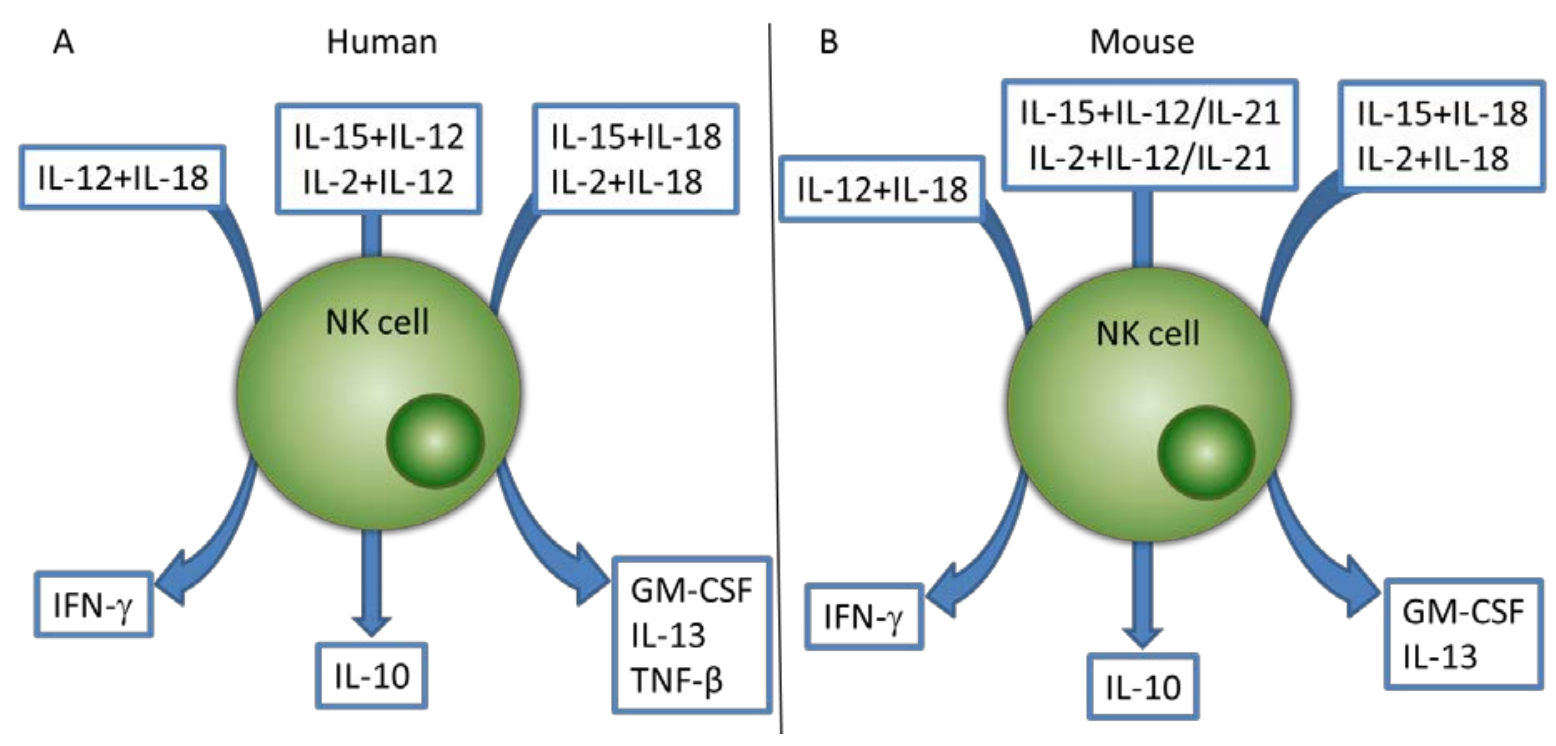

Figure 1. Effect of cytokines on NK cell cytokine production in vitro

(A) Human NK cells produce mainly IFN- $\gamma$ upon stimulation with IL-12 and IL-18. IL-10 is mainly induced by IL-2 or IL-15 synergized by IL-12, whereas IL-2 or IL-15 together with IL-18 stimulate GM-CSF, IL-13 and TNF- $\beta$ release. (B) Mouse NK cells produce IFN- $\gamma$ upon stimulation with IL-12 and IL-18. IL-12 or IL-21 stimulates IL-10 production and IL-18 induces GM-CSF and IL-13 production when combined to IL-15 or IL-2. 


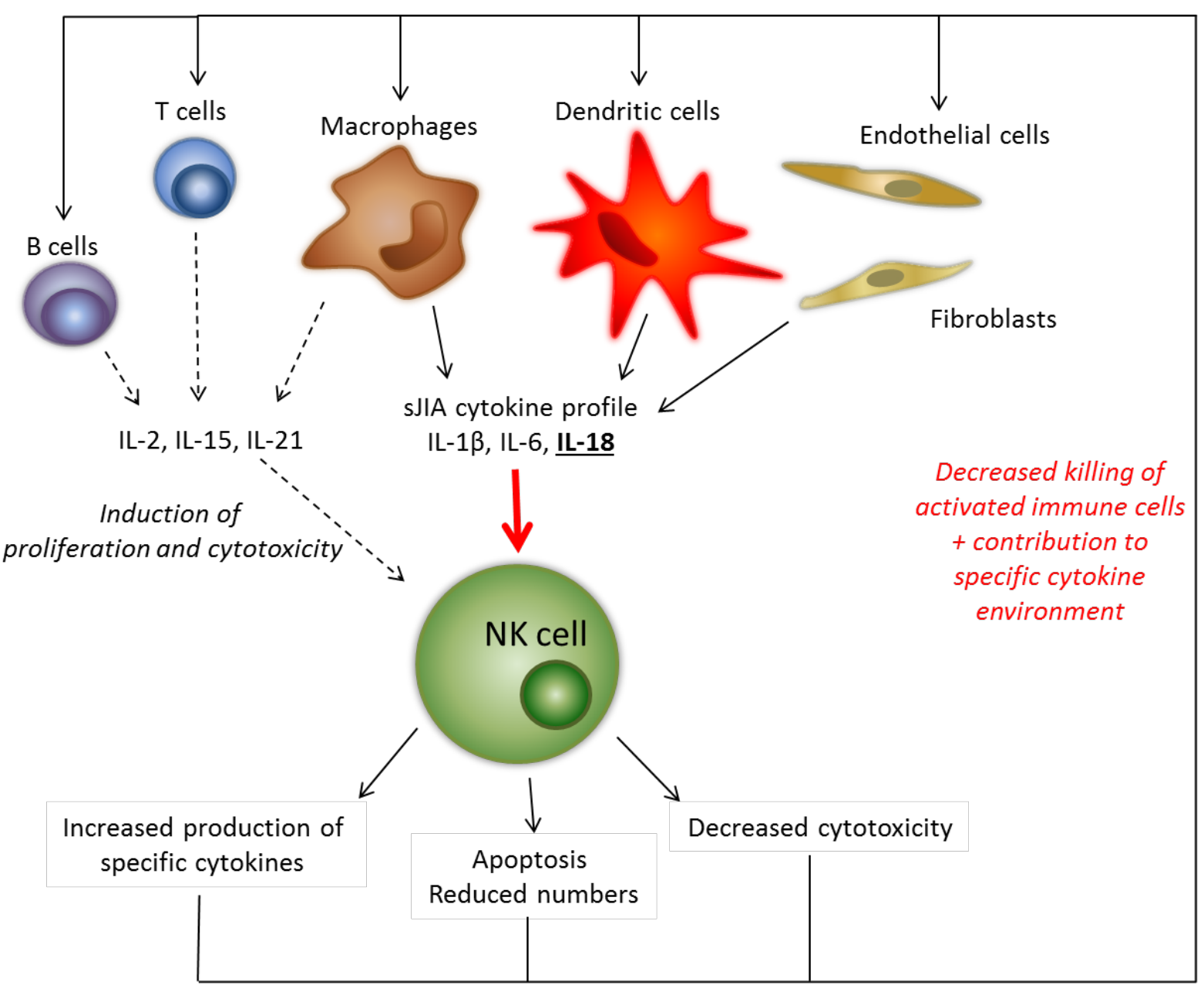

Figure 2. Proposed mechanism for decreased NK cell function in SJIA

The specific cytokine profile of sJIA patients, i.e. high levels of IL-1 $\beta$, IL-6 and IL-18, may be the result of overactivated (innate) immune cells, endothelial cells and fibroblasts. This cytokine environment rather induces a cytokine-producing NK cell phenotype, with increased production of specific cytokines, increased apoptosis and decreased cytotoxicity. The presence of cytokines like IL-2, IL-15 and IL-21, that induce proliferation and cytotoxicity, may be less explicit (dotted line). As a consequence, NK cell number and cytotoxic function are depressed, resulting in a defective termination of the immune response. 
Reference List

[1] Petty RE, Southwood TR, Manners P, Baum J, Glass DN, Goldenberg J et al. International League of Associations for Rheumatology classification of juvenile idiopathic arthritis: second revision, Edmonton, 2001. J Rheumatol 2004; 31(2):390-2.

[2] Mellins ED, Macaubas C, Grom AA. Pathogenesis of systemic juvenile idiopathic arthritis: some answers, more questions. Nat Rev Rheumatol 2011; 7(7):416-26.

[3] Ravelli A, Martini A. Juvenile idiopathic arthritis. Lancet 2007; 369(9563):767-78.

[4] Grom AA, Mellins ED. Macrophage activation syndrome: advances towards understanding pathogenesis. Curr Opin Rheumatol 2010; 22(5):561-6.

[5] Kelly A, Ramanan AV. Recognition and management of macrophage activation syndrome in juvenile arthritis. Curr Opin Rheumatol 2007; 19(5):477-81.

[6] Janka GE. Familial and acquired hemophagocytic lymphohistiocytosis. Annu Rev Med 2012; 63:233-46.

[7] Jordan MB, Allen CE, Weitzman S, Filipovich AH, McClain KL. How I treat hemophagocytic lymphohistiocytosis. Blood 2011; 118(15):4041-52.

[8] de Jager W, Vastert SJ, Beekman JM, Wulffraat NM, Kuis W, Coffer PJ et al. Defective phosphorylation of interleukin-18 receptor beta causes impaired natural killer cell function in systemic-onset juvenile idiopathic arthritis. Arthritis Rheum 2009; 60(9):2782-93.

[9] Grom AA. Natural killer cell dysfunction: A common pathway in systemic-onset juvenile rheumatoid arthritis, macrophage activation syndrome, and hemophagocytic lymphohistiocytosis? Arthritis Rheum 2004; 50(3):689-98.

[10] Villanueva J, Lee S, Giannini EH, Graham TB, Passo MH, Filipovich A et al. Natural killer cell dysfunction is a distinguishing feature of systemic onset juvenile rheumatoid arthritis and macrophage activation syndrome. Arthritis Res Ther 2005; 7(1):R30-R37.

[11] Vastert SJ, Kuis W, Grom AA. Systemic JIA: new developments in the understanding of the pathophysiology and therapy. Best Pract Res Clin Rheumatol 2009; 23(5):655-64.

[12] de Benedetti F., Schneider R. Systemic juvenile idiopathic arthritis. In: Cassidy JT, Laxer RM, Petty RE, Lindsey CB, eds. Textbook of Pediatric Rheumatology. Philadelphia, PA: Saunders; 2011:236-248.

[13] Gabay C, Lamacchia C, Palmer G. IL-1 pathways in inflammation and human diseases. Nat Rev Rheumatol 2010; 6(4):232-41.

[14] Arend WP, Palmer G, Gabay C. IL-1, IL-18, and IL-33 families of cytokines. Immunol Rev 2008; 223:20-38.

[15] Stock CJ, Ogilvie EM, Samuel JM, Fife M, Lewis CM, Woo P. Comprehensive association study of genetic variants in the IL-1 gene family in systemic juvenile idiopathic arthritis. Genes Immun 2008; 9(4):349-57. 
[16] Lotito AP, Campa A, Silva CA, Kiss MH, Mello SB. Interleukin 18 as a marker of disease activity and severity in patients with juvenile idiopathic arthritis. J Rheumatol 2007; 34(4):823-30.

[17] Prahalad S, Martins TB, Tebo AE, Whiting A, Clifford B, Zeft AS et al. Elevated serum levels of soluble CD154 in children with juvenile idiopathic arthritis. Pediatr Rheumatol Online J 2008; 6:8.

[18] Yilmaz M, Kendirli SG, Altintas D, Bingol G, Antmen B. Cytokine levels in serum of patients with juvenile rheumatoid arthritis. Clin Rheumatol 2001; 20(1):30-5.

[19] Ogilvie EM, Khan A, Hubank M, Kellam P, Woo P. Specific gene expression profiles in systemic juvenile idiopathic arthritis. Arthritis Rheum 2007; 56(6):1954-65.

[20] Barnes MG, Grom AA, Thompson SD, Griffin TA, Pavlidis P, Itert L et al. Subtype-specific peripheral blood gene expression profiles in recent-onset juvenile idiopathic arthritis. Arthritis Rheum 2009; 60(7):2102-12.

[21] Fall N, Barnes M, Thornton S, Luyrink L, Olson J, llowite NT et al. Gene expression profiling of peripheral blood from patients with untreated new-onset systemic juvenile idiopathic arthritis reveals molecular heterogeneity that may predict macrophage activation syndrome. Arthritis Rheum 2007; 56(11):3793-804.

[22] Allantaz F, Chaussabel D, Stichweh D, Bennett L, Allman W, Mejias A et al. Blood leukocyte microarrays to diagnose systemic onset juvenile idiopathic arthritis and follow the response to IL-1 blockade. J Exp Med 2007; 204(9):2131-44.

[23] Rooney M, David J, Symons J, Di GF, Varsani H, Woo P. Inflammatory cytokine responses in juvenile chronic arthritis. Br J Rheumatol 1995; 34(5):454-60.

[24] De Benedetti F, Pignatti P, Massa M, Sartirana P, Ravelli A, Martini A. Circulating levels of interleukin 1 beta and of interleukin 1 receptor antagonist in systemic juvenile chronic arthritis. Clin Exp Rheumatol 1995; 13(6):779-84.

[25] de Jager W, Hoppenreijs EP, Wulffraat NM, Wedderburn LR, Kuis W, Prakken BJ. Blood and synovial fluid cytokine signatures in patients with juvenile idiopathic arthritis: a crosssectional study. Ann Rheum Dis 2007; 66(5):589-98.

[26] Pascual V, Allantaz F, Arce E, Punaro M, Banchereau J. Role of interleukin-1 (IL-1) in the pathogenesis of systemic onset juvenile idiopathic arthritis and clinical response to IL-1 blockade. J Exp Med 2005; 201(9):1479-86.

[27] Muller K, Herner EB, Stagg A, Bendtzen K, Woo P. Inflammatory cytokines and cytokine antagonists in whole blood cultures of patients with systemic juvenile chronic arthritis. $\mathrm{Br} \mathrm{J}$ Rheumatol 1998; 37(5):562-9.

[28] Gattorno M, Piccini A, Lasiglie D, Tassi S, Brisca G, Carta S et al. The pattern of response to anti-interleukin-1 treatment distinguishes two subsets of patients with systemic-onset juvenile idiopathic arthritis. Arthritis Rheum 2008; 58(5):1505-15.

[29] Verbsky JW, White AJ. Effective use of the recombinant interleukin 1 receptor antagonist anakinra in therapy resistant systemic onset juvenile rheumatoid arthritis. J Rheumatol 2004; 31(10):2071-5. 
[30] Quartier P, Allantaz F, Cimaz R, Pillet P, Messiaen C, Bardin C et al. A multicentre, randomised, double-blind, placebo-controlled trial with the interleukin-1 receptor antagonist anakinra in patients with systemic-onset juvenile idiopathic arthritis (ANAJIS trial). Ann Rheum Dis 2011; 70(5):747-54.

[31] Ruperto N, Brunner HI, Quartier P, Constantin T, Wulffraat N, Horneff G et al. Two randomized trials of canakinumab in systemic juvenile idiopathic arthritis. N Engl J Med 2012; 367(25):2396-406.

[32] Macaubas C, Nguyen KD, Peck A, Buckingham J, Deshpande C, Wong E et al. Alternative activation in systemic juvenile idiopathic arthritis monocytes. Clin Immunol 2012; 142(3):36272.

[33] Fishman D, Faulds G, Jeffery R, Mohamed-Ali V, Yudkin JS, Humphries S et al. The effect of novel polymorphisms in the interleukin-6 (IL-6) gene on IL-6 transcription and plasma IL-6 levels, and an association with systemic-onset juvenile chronic arthritis. J Clin Invest 1998; 102(7):1369-76.

[34] Ogilvie EM, Fife MS, Thompson SD, Twine N, Tsoras M, Moroldo M et al. The -174 G allele of the interleukin- 6 gene confers susceptibility to systemic arthritis in children: a multicenter study using simplex and multiplex juvenile idiopathic arthritis families. Arthritis Rheum 2003; 48(11):3202-6.

[35] Pignatti P, Vivarelli M, Meazza C, Rizzolo MG, Martini A, De BF. Abnormal regulation of interleukin 6 in systemic juvenile idiopathic arthritis. J Rheumatol 2001; 28(7):1670-6.

[36] de Benedetti F, Meazza C, Oliveri M, Pignatti P, Vivarelli M, Alonzi T et al. Effect of IL-6 on IGF binding protein-3: a study in IL-6 transgenic mice and in patients with systemic juvenile idiopathic arthritis. Endocrinology 2001; 142(11):4818-26.

[37] de Benedetti F, Massa M, Robbioni P, Ravelli A, Burgio GR, Martini A. Correlation of serum interleukin-6 levels with joint involvement and thrombocytosis in systemic juvenile rheumatoid arthritis. Arthritis Rheum 1991; 34(9):1158-63.

[38] Cazzola M, Ponchio L, de BF, Ravelli A, Rosti V, Beguin $Y$ et al. Defective iron supply for erythropoiesis and adequate endogenous erythropoietin production in the anemia associated with systemic-onset juvenile chronic arthritis. Blood 1996; 87(11):4824-30.

[39] Shimizu M, Yachie A. Compensated inflammation in systemic juvenile idiopathic arthritis: role of alternatively activated macrophages. Cytokine 2012; 60(1):226-32.

[40] Lepore L, Pennesi M, Saletta S, Perticarari S, Presani G, Prodan M. Study of IL-2, IL-6, TNF alpha, IFN gamma and beta in the serum and synovial fluid of patients with juvenile chronic arthritis. Clin Exp Rheumatol 1994; 12(5):561-5.

[41] Hinze CH, Fall N, Thornton S, Mo JQ, Aronow BJ, Layh-Schmitt G et al. Immature cell populations and an erythropoiesis gene-expression signature in systemic juvenile idiopathic arthritis: implications for pathogenesis. Arthritis Res Ther 2010; 12(3):R123.

[42] de Benedetti F, Brunner HI, Ruperto N, Kenwright A, Wright S, Calvo I et al. Randomized trial of tocilizumab in systemic juvenile idiopathic arthritis. N Engl J Med 2012; 367(25):2385-95. 
[43] Fife MS, Gutierrez A, Ogilvie EM, Stock CJ, Samuel JM, Thomson W et al. Novel IL10 gene family associations with systemic juvenile idiopathic arthritis. Arthritis Res Ther 2006; 8(5):R148.

[44] Moller JC, Paul D, Ganser G, Range U, Gahr M, Kelsch R et al. IL10 promoter polymorphisms are associated with systemic onset juvenile idiopathic arthritis (SoJIA). Clin Exp Rheumatol 2010; 28(6):912-8.

[45] Raziuddin S, Bahabri S, al-Dalaan A, Siraj AK, al-Sedairy S. A mixed Th1/Th2 cell cytokine response predominates in systemic onset juvenile rheumatoid arthritis: immunoregulatory IL-10 function. Clin Immunol Immunopathol 1998; 86(2):192-8.

[46] Roark CL, Simonian PL, Fontenot AP, Born WK, O'Brien RL. gammadelta T cells: an important source of IL-17. Curr Opin Immunol 2008; 20(3):353-7.

[47] Omoyinmi E, Hamaoui R, Pesenacker A, Nistala K, Moncrieffe H, Ursu S et al. Th1 and Th17 cell subpopulations are enriched in the peripheral blood of patients with systemic juvenile idiopathic arthritis. Rheumatology (Oxford) 2012; 51(10):1881-6.

[48] Shimizu M, Nakagishi Y, Kasai K, Yamasaki Y, Miyoshi M, Takei S et al. Tocilizumab masks the clinical symptoms of systemic juvenile idiopathic arthritis-associated macrophage activation syndrome: the diagnostic significance of interleukin-18 and interleukin-6. Cytokine 2012; $58(2): 287-94$.

[49] Shimizu M, Yokoyama T, Yamada K, Kaneda H, Wada H, Wada T et al. Distinct cytokine profiles of systemic-onset juvenile idiopathic arthritis-associated macrophage activation syndrome with particular emphasis on the role of interleukin-18 in its pathogenesis. Rheumatology (Oxford) 2010; 49(9):1645-53.

[50] Chen O, Shan N, Zhu X, Wang Y, Ren P, Wei D et al. The imbalance of IL-18/IL-18BP in patients with systemic juvenile idiopathic arthritis. Acta Biochim Biophys Sin (Shanghai) 2013; 45(4):339-41.

[51] Date $\mathrm{Y}$, Seki N, Kamizono S, Higuchi T, Hirata T, Miyata K et al. Identification of a genetic risk factor for systemic juvenile rheumatoid arthritis in the $5^{\prime}$-flanking region of the TNFalpha gene and HLA genes. Arthritis Rheum 1999; 42(12):2577-82.

[52] Quartier P, Taupin P, Bourdeaut F, Lemelle I, Pillet P, Bost M et al. Efficacy of etanercept for the treatment of juvenile idiopathic arthritis according to the onset type. Arthritis Rheum 2003; 48(4):1093-101.

[53] Billiau A, Matthys P. Interferon-gamma: a historical perspective. Cytokine Growth Factor Rev 2009; 20(2):97-113.

[54] Osugi Y, Hara J, Tagawa S, Takai K, Hosoi G, Matsuda Y et al. Cytokine production regulating Th1 and Th2 cytokines in hemophagocytic lymphohistiocytosis. Blood 1997; 89(11):4100-3.

[55] Akashi K, Hayashi S, Gondo H, Mizuno S, Harada M, Tamura K et al. Involvement of interferon-gamma and macrophage colony-stimulating factor in pathogenesis of haemophagocytic lymphohistiocytosis in adults. Br J Haematol 1994; 87(2):243-50. 
[56] Jordan MB, Hildeman D, Kappler J, Marrack P. An animal model of hemophagocytic lymphohistiocytosis (HLH): CD8+ T cells and interferon gamma are essential for the disorder. Blood 2004; 104(3):735-43.

[57] Pachlopnik SJ, Ho CH, Chretien F, Lefebvre JM, Pivert G, Kosco-Vilbois M et al. Neutralization of IFNgamma defeats haemophagocytosis in LCMV-infected perforin- and Rab27a-deficient mice. EMBO Mol Med 2009; 1(2):112-24.

[58] Mazodier K, Marin V, Novick D, Farnarier C, Robitail S, Schleinitz N et al. Severe imbalance of IL-18/IL-18BP in patients with secondary hemophagocytic syndrome. Blood 2005; 106(10):3483-9.

[59] Billiau AD, Roskams T, Van Damme-Lombaerts R, Matthys P, Wouters C. Macrophage activation syndrome: characteristic findings on liver biopsy illustrating the key role of activated, IFN-gamma-producing lymphocytes and IL-6- and TNF-alpha-producing macrophages. Blood 2005; 105(4):1648-51.

[60] Ishikawa S, Mima T, Aoki C, Yoshio-Hoshino N, Adachi Y, Imagawa T et al. Abnormal expression of the genes involved in cytokine networks and mitochondrial function in systemic juvenile idiopathic arthritis identified by DNA microarray analysis. Ann Rheum Dis 2009; 68(2):264-72.

[61] Sikora KA, Fall N, Thornton S, Grom AA. The limited role of interferon-gamma in systemic juvenile idiopathic arthritis cannot be explained by cellular hyporesponsiveness. Arthritis Rheum 2012; 64(11):3799-808.

[62] Canna SW. Interferon- gamma: Friend or Foe in Systemic Juvenile Idiopathic Arthritis and Adult Still's Disease. Arthritis Rheumatol 2014.

[63] Shimizu M, Nakagishi $Y$, Yachie A. Distinct subsets of patients with systemic juvenile idiopathic arthritis based on their cytokine profiles. Cytokine 2013; 61(2):345-8.

[64] de Benedetti F, Alonzi T, Moretta A, Lazzaro D, Costa P, Poli V et al. Interleukin 6 causes growth impairment in transgenic mice through a decrease in insulin-like growth factor-I. A model for stunted growth in children with chronic inflammation. J Clin Invest 1997; 99(4):643-50.

[65] Strippoli R, Carvello F, Scianaro R, Pasquale LD, Vivarelli M, Petrini S et al. Chronic exposure to interleukin-6 amplifies the response to toll-like receptor ligands: Implication on the pathogenesis of macrophage activation syndrome. Arthritis Rheum 2011.

[66] Kawane K, Tanaka H, Kitahara Y, Shimaoka S, Nagata S. Cytokine-dependent but acquired immunity-independent arthritis caused by DNA escaped from degradation. Proc Natl Acad Sci U S A 2010; 107(45):19432-7.

[67] Avau A, Mitera T, Put S, Put K, Brisse E, Filtjens J et al. Systemic Juvenile Idiopathic Arthritislike Syndrome in Mice Following Stimulation of the Immune System With Freund's Complete Adjuvant: Regulation by Interferon-gamma. Arthritis Rheumatol 2014; 66(5):1340-51.

[68] Dungan LS, Mills KH. Caspase-1-processed IL-1 family cytokines play a vital role in driving innate IL-17. Cytokine 2011; 56(1):126-32. 
[69] Canna SW, Wrobel J, Chu N, Kreiger PA, Paessler M, Behrens EM. Interferon-gamma mediates anemia but is dispensable for fulminant toll-like receptor 9-induced macrophage activation syndrome and hemophagocytosis. Arthritis Rheum 2013; 65(7):1764-75.

[70] Behrens EM, Canna SW, Slade K, Rao S, Kreiger PA, Paessler M et al. Repeated TLR9 stimulation results in macrophage activation syndrome-like disease in mice. J Clin Invest 2011; 121(6):2264-77.

[71] Vivier E, Tomasello E, Baratin M, Walzer T, Ugolini S. Functions of natural killer cells. Nat Immunol 2008; 9(5):503-10.

[72] Biron CA, Nguyen KB, Pien GC, Cousens LP, Salazar-Mather TP. Natural killer cells in antiviral defense: function and regulation by innate cytokines. Annu Rev Immunol 1999; 17:189-220.

[73] Smyth MJ, Cretney E, Kelly JM, Westwood JA, Street SE, Yagita $\mathrm{H}$ et al. Activation of NK cell cytotoxicity. Mol Immunol 2005; 42(4):501-10.

[74] Cooper MA, Fehniger TA, Turner SC, Chen KS, Ghaheri BA, Ghayur T et al. Human natural killer cells: a unique innate immunoregulatory role for the CD56(bright) subset. Blood 2001; 97(10):3146-51.

[75] Hallett WH, Murphy WJ. Positive and negative regulation of Natural Killer cells: therapeutic implications. Semin Cancer Biol 2006; 16(5):367-82.

[76] Dalton DK, Pitts-Meek S, Keshav S, Figari IS, Bradley A, Stewart TA. Multiple defects of immune cell function in mice with disrupted interferon-gamma genes. Science 1993; 259(5102):1739-42.

[77] Takeda K, Tsutsui H, Yoshimoto T, Adachi O, Yoshida N, Kishimoto T et al. Defective NK cell activity and Th1 response in IL-18-deficient mice. Immunity 1998; 8(3):383-90.

[78] Orange JS, Biron CA. An absolute and restricted requirement for IL-12 in natural killer cell IFN-gamma production and antiviral defense. Studies of natural killer and T cell responses in contrasting viral infections. J Immunol 1996; 156(3):1138-42.

[79] Kennedy MK, Glaccum M, Brown SN, Butz EA, Viney JL, Embers M et al. Reversible defects in natural killer and memory CD8 T cell lineages in interleukin 15-deficient mice. J Exp Med 2000; 191(5):771-80.

[80] Fehniger TA, Shah MH, Turner MJ, VanDeusen JB, Whitman SP, Cooper MA et al. Differential cytokine and chemokine gene expression by human NK cells following activation with IL-18 or IL-15 in combination with IL-12: implications for the innate immune response. J Immunol 1999; 162(8):4511-20.

[81] Mehrotra PT, Donnelly RP, Wong S, Kanegane H, Geremew A, Mostowski HS et al. Production of IL-10 by human natural killer cells stimulated with IL-2 and/or IL-12. J Immunol 1998; 160(6):2637-44.

[82] Brady J, Carotta S, Thong RP, Chan CJ, Hayakawa Y, Smyth MJ et al. The interactions of multiple cytokines control NK cell maturation. J Immunol 2010; 185(11):6679-88.

[83] Brady J, Hayakawa Y, Smyth MJ, Nutt SL. IL-21 induces the functional maturation of murine NK cells. J Immunol 2004; 172(4):2048-58. 
[84] Hoshino T, Wiltrout RH, Young HA. IL-18 is a potent coinducer of IL-13 in NK and T cells: a new potential role for IL-18 in modulating the immune response. J Immunol 1999; 162(9):5070-7.

[85] Grant LR, Yao ZJ, Hedrich CM, Wang F, Moorthy A, Wilson K et al. Stat4-dependent, T-betindependent regulation of IL-10 in NK cells. Genes Immun 2008; 9(4):316-27.

[86] Macaubas C, Nguyen K, Deshpande C, Phillips C, Peck A, Lee T et al. Distribution of circulating cells in systemic juvenile idiopathic arthritis across disease activity states. Clin Immunol 2010; 134(2):206-16.

[87] Wouters $\mathrm{CH}$, Ceuppens JL, Stevens EA. Different circulating lymphocyte profiles in patients with different subtypes of juvenile idiopathic arthritis. Clin Exp Rheumatol 2002; 20(2):23948.

[88] Zhou J, Tang X, Ding Y, An Y, Zhao X. Natural killer cell activity and frequency of killer cell immunoglobulin-like receptors in children with different forms of juvenile idiopathic arthritis. Pediatr Allergy Immunol 2013; 24(7):691-6.

[89] Shibatomi K, Ida H, Yamasaki S, Nakashima T, Origuchi T, Kawakami A et al. A novel role for interleukin-18 in human natural killer cell death: high serum levels and low natural killer cell numbers in patients with systemic autoimmune diseases. Arthritis Rheum 2001; 44(4):88492.

[90] Park YW, Kee SJ, Cho YN, Lee EH, Lee HY, Kim EM et al. Impaired differentiation and cytotoxicity of natural killer cells in systemic lupus erythematosus. Arthritis Rheum 2009; 60(6):1753-63.

[91] Wong CK, Li EK, Ho CY, Lam CW. Elevation of plasma interleukin-18 concentration is correlated with disease activity in systemic lupus erythematosus. Rheumatology (Oxford) 2000; 39(10):1078-81.

[92] Iannello A, Samarani S, Debbeche O, Ahmad R, Boulassel MR, Tremblay C et al. Potential role of interleukin-18 in the immunopathogenesis of AIDS: involvement in fratricidal killing of NK cells. J Virol 2009; 83(12):5999-6010.

[93] Grom AA, Villanueva J, Lee S, Goldmuntz EA, Passo MH, Filipovich A. Natural killer cell dysfunction in patients with systemic-onset juvenile rheumatoid arthritis and macrophage activation syndrome. J Pediatr 2003; 142(3):292-6.

[94] Wulffraat NM, Rijkers GT, Elst E, Brooimans R, Kuis W. Reduced perforin expression in systemic juvenile idiopathic arthritis is restored by autologous stem-cell transplantation. Rheumatology (Oxford) 2003; 42(2):375-9.

[95] Vastert SJ, van Wijk R, D'Urbano LE, de Vooght KM, de Jager W, Ravelli A et al. Mutations in the perforin gene can be linked to macrophage activation syndrome in patients with systemic onset juvenile idiopathic arthritis. Rheumatology (Oxford) 2010; 49(3):441-9.

[96] Vastert SJ, Kuis W, Grom AA. Systemic JIA: new developments in the understanding of the pathophysiology and therapy. Best Pract Res Clin Rheumatol 2009; 23(5):655-64. 
[97] Henriques A, Teixeira L, Ines L, Carvalheiro T, Goncalves A, Martinho A et al. NK cells dysfunction in systemic lupus erythematosus: relation to disease activity. Clin Rheumatol 2013; 32(6):805-13.

[98] Scheid C, Young R, McDermott R, Fitzsimmons L, Scarffe JH, Stern PL. Immune function of patients receiving recombinant human interleukin-6 (IL-6) in a phase I clinical study: induction of C-reactive protein and IgE and inhibition of natural killer and lymphokineactivated killer cell activity. Cancer Immunol Immunother 1994; 38(2):119-26.

[99] Maroof A, Beattie L, Zubairi S, Svensson M, Stager S, Kaye PM. Posttranscriptional regulation of II10 gene expression allows natural killer cells to express immunoregulatory function. Immunity 2008; 29(2):295-305.

[100] Perona-Wright G, Mohrs K, Szaba FM, Kummer LW, Madan R, Karp CL et al. Systemic but not local infections elicit immunosuppressive IL-10 production by natural killer cells. Cell Host Microbe 2009; 6(6):503-12.

[101] Sawhney S, Woo P, Murray KJ. Macrophage activation syndrome: a potentially fatal complication of rheumatic disorders. Arch Dis Child 2001; 85(5):421-6.

[102] Behrens EM, Beukelman T, Gallo L, Spangler J, Rosenkranz M, Arkachaisri T et al. Evaluation of the presentation of systemic onset juvenile rheumatoid arthritis: data from the Pennsylvania Systemic Onset Juvenile Arthritis Registry (PASOJAR). J Rheumatol 2008; 35(2):343-8.

[103] Ravelli A, Grom AA, Behrens EM, Cron RQ. Macrophage activation syndrome as part of systemic juvenile idiopathic arthritis: diagnosis, genetics, pathophysiology and treatment. Genes Immun 2012; 13(4):289-98.

[104] Ravelli A. Macrophage activation syndrome. Curr Opin Rheumatol 2002; 14(5):548-52.

[105] Lehmberg K, Pink I, Eulenburg C, Beutel K, Maul-Pavicic A, Janka G. Differentiating macrophage activation syndrome in systemic juvenile idiopathic arthritis from other forms of hemophagocytic lymphohistiocytosis. J Pediatr 2013; 162(6):1245-51.

[106] Henter JI, Horne A, Arico M, Egeler RM, Filipovich AH, Imashuku S et al. HLH-2004: Diagnostic and therapeutic guidelines for hemophagocytic lymphohistiocytosis. Pediatr Blood Cancer 2007; 48(2):124-31.

[107] Gholam C, Grigoriadou S, Gilmour KC, Gaspar HB. Familial haemophagocytic lymphohistiocytosis: advances in the genetic basis, diagnosis and management. Clin Exp Immunol 2011; 163(3):271-83.

[108] Filipovich AH. Hemophagocytic lymphohistiocytosis (HLH) and related disorders. Hematology Am Soc Hematol Educ Program 2009;127-31.

[109] Henter JI, Tondini C, Pritchard J. Histiocyte disorders. Crit Rev Oncol Hematol 2004; 50(2):157-74.

[110] Janka GE. Hemophagocytic syndromes. Blood Rev 2007; 21(5):245-53.

[111] Weitzman S. Approach to hemophagocytic syndromes. Hematology Am Soc Hematol Educ Program 2011; 2011:178-83. 
[112] Henter JI, Elinder G, Soder O, Ost A. Incidence in Sweden and clinical features of familial hemophagocytic lymphohistiocytosis. Acta Paediatr Scand 1991; 80(4):428-35.

[113] De Benedetti F, Massa M, Pignatti P, Kelley M, Faltynek CR, Martini A. Elevated circulating interleukin-7 levels in patients with systemic juvenile rheumatoid arthritis. J Rheumatol 1995; 22(8):1581-5. 